\title{
ESTRUTURA ORGANIZACIONAL E GOVERNANÇA: UM ESTUDO DE CASO EM UMA
}

\section{INSTITUIÇÃO COOPERATIVISTA}

Organizational structure and governance: a case study in a cooperative institution

\author{
Larissa Araújo Pereira ${ }^{1}$ \\ Natália Almeida Picinin² \\ Edrilene Barbosa Lima Justi ${ }^{3}$ \\ Jamson Justi ${ }^{4}$ \\ Jadson Justi ${ }^{5}$ \\ Victor Antunes de Souza Serrão ${ }^{6}$ \\ Recebido em: 09 maio 2018 \\ Aceito em: 13 dez. 2018
}

Resumo: Esta pesquisa apresenta uma análise conceitual de estrutura organizacional e uma síntese do sistema cooperativista. Leva em consideração temáticas organizacionais de forma a evidenciar as estruturas modernas relatando sobre as práticas de governança, que, contemporaneamente, têm ganhado destaque no universo corporativo, quando o assunto é gerenciamento das organizações e redução de riscos. Este estudo tem por objetivo verificar de que forma os conceitos de estrutura organizacional e governança podem ser desenvolvidos em uma organização cooperativista e que influências essas definições trazem para o ambiente da organização. Metodologicamente, engendra-se como um estudo de caso, descritivo com abordagem qualitativa, sendo estruturado em aspectos conceituais, contextuais e embasados na coleta de dados, que ocorreu por intermédio de pesquisa in loco. Os dados coletados evidenciam que a cooperativa estudada deve instituir, de forma objetiva e consensual, programas de capacitação com o programa de formação de dirigentes e conselheiros na área de capacitação em governança cooperativa e gestão de cooperativa. Conclui-se que o desafio de uma mudança na estrutura organizacional, e na própria cultura, parte dos cooperados e gestores que devem buscar o desenvolvimento ou ampliação dos processos e as práticas referentes à tomada de decisões, otimizando a comunicação e a relação dos envolvidos, aperfeiçoando o conhecimento da gestão, e maximizando a transparência dos administradores e do próprio negócio.

Palavras-Chave: Estrutura organizacional. Governança corporativa. Cooperativa.

Abstract: This research presents a conceptual analysis of organizational structure and a synthesis of the cooperative system. It takes into consideration organizational themes in

\footnotetext{
${ }^{1}$ Universidade Federal de Mato Grosso do Sul. E-mail: larissa_araujo03@hotmail.com.

2 Universidade Federal de Mato Grosso do Sul. E-mail: natalia01picinin@hotmail.com.

${ }^{3}$ Universidade Federal de Mato Grosso do Sul. E-mail: edrilene@gmail.com.

${ }^{4}$ Universidade Federal de Mato Grosso do Sul. E-mail: jamsonjusti@yahoo.com.br.

${ }^{5}$ Universidade Federal do Amazonas. E-mail: jadsonjusti@hotmail.com.

${ }^{6}$ Universidade Federal do Amazonas. E-mail: victorantunes2016@gmail.com.
} 
order to show the modern structures reporting on the practices of governance, which, at the same time, have gained prominence in the corporate universe when it comes to managing organizations and reducing risks. This study aims to verify how the concepts of organizational structure and governance can be developed in a cooperative organization and what influences these definitions bring to the organization's environment. Methodologically, it is generated as a case study, descriptive with a qualitative approach, being structured in conceptual, contextual and based aspects in the data collection, which occurred through in loco research. The collected data show that the cooperative studied should institute, in an objective and consensual way, training programs with the training program of leaders and advisers in the area of training in cooperative governance and cooperative management. It is concluded that the challenge of a change in the organizational structure, and in the culture itself, is part of the cooperative and managers who must seek the development or expansion of processes and practices regarding decision making, optimizing the communication and the relationship of those involved, improving management knowledge, and maximizing the transparency of managers and the business itself.

Keywords: Organizational structure. Corporate governance. Cooperative.

\section{INTRODUÇÃO}

O mercado contemporâneo vem se tornando cada vez mais competitivo, exigindo das organizações um diferencial no mercado em que atuam, e, para que isso ocorra, é necessário que elas tenham uma estrutura organizacional qualificada, para atender suas expectativas e necessidades. Uma gestão eficiente é uma proposta inovadora na estrutura organizacional das empresas em geral, proporcionando, assim, uma perspectiva mais ampla, que, se bemdesenvolvida, produz efeitos positivos no mercado.

Seguindo o pensamento contemporâneo, as empresas devem adequar seus padrões e regimentos, a fim de se estabilizar e progredir no mercado. Desse modo, a governança corporativa auxilia nas tomadas de decisões e na melhor forma de como atingir seus objetivos, monitorando os relacionamentos entre empresa e associados, qualificando a organização, impulsionando as competências de dirigentes, acionistas e colaboradores, agregando valor e maximizando o resultado.

Portanto, a questão-chave deste trabalho é: como a estrutura organizacional e a governança se aplicam em uma instituição cooperativa? Nesse sentido, este artigo tem por objetivo verificar de que forma os conceitos de estrutura organizacional e governança podem ser desenvolvidos em uma organização cooperativista e que influências essas definições trazem para o ambiente da organização. A empresa em estudo trata-se de uma cooperativa agroindustrial, contextualizando o que vem sendo trabalhado, e o que deve ser agregado em sua estrutura, a fim de aperfeiçoar suas políticas organizacionais. 


\section{ESTRUTURA ORGANIZACIONAL}

$\mathrm{Na}$ sociedade moderna, todas as organizações estão presentes nas atividades cotidianas comunitárias, sendo inevitáveis, por exemplo, a compra de um pão, que envolve um processo organizacional desde a compra da matéria-prima até a comercialização do produto. Segundo Chiavenato (2007), a sociedade moderna é considerada como uma sociedade industrializada, que parte do pressuposto de que o homem depende das organizações desde seu nascer, ou até mesmo ganhar a sua própria remuneração, assim ficando evidente que são fatores essenciais para sua sobrevivência. "[...] Historicamente, o objetivo das estruturas organizacionais era institucionalizar a estabilidade. Na empresa do futuro, o objetivo do desenho [organizacional] será institucionalizar as mudanças." (NADLER; TUSHMAN, 2000, p. 59).

Para que a organização alcance uma produtividade eficiente e rentabilidade nas suas atividades, é necessário que exista uma estrutura organizacional elaborada. Essa mesma estrutura é considerada como uma perspectiva relativa à atividade gerencial, envolvendo em sua metodologia um conjunto de inter-relações que oportuniza a execução do trabalho (SBRAGIA, 1980). É válido destacar que a estrutura organizacional interfere na relação do trabalho das pessoas. Ou seja, cada trabalhador de uma organização distinta está submetido a uma estrutura, influenciando o comportamento e sua agregação no ambiente em que trabalha. Assim, cada indivíduo tem um perfil que age mutuamente com o perfil da organização. Podese dizer que a estrutura organizacional caracteriza um elo entre seus trabalhadores, abrangendo um compartilhamento por deveres ou ocupações diferentes, havendo assim uma divisão do trabalho, sempre obedecendo às políticas e às normas estabelecidas pela organização (MÜLBERT; MUSSI; ANGELONI, 2008).

A estrutura organizacional define-se pelos métodos no qual a empresa é administrada. Esse critério possui três características essenciais, segundo Santos, Silva e Guimarães (2014): a) desempenhar produtos e objetivos organizacionais; b) normalizar a atuação das oscilações dentro da organização; c) evidencia a forma de como o poder é executado, estabelecendo as decisões e tarefas. Conforme Costa, Souza e Fell (2012), é de extrema importância que uma instituição tenha uma estrutura organizacional, pois nela consiste em apontar o poder, auxiliar e definir o processo decisório, aumentar a comunicação, seja em um formato horizontal ou vertical, formalização, participação e as especializações. Assim, para que a organização tenha um melhor funcionamento, é necessário que haja um controle e que tenha divisão de tarefas e responsabilidades.

\section{ESTRUTURA ORGANIZACIONAL COOPERATIVISTA}

Para as cooperativas, a estrutura organizacional é considerada como um processo 
administrativo, estabelecendo identificação, análise, ordenação e agrupamento das atividades e recursos a fim de determinar os pontos ascendentes e processo decisório, nele identificando os objetivos assinalados, sejam no planejamento estratégico, tático ou operacional (OLIVEIRA, 2012).

Para Vasconcellos e Hemsley (1997), os elementos da estrutura organizacional são determinados em quatro fatores:

a) responsabilidade: obrigação que uma pessoa ou uma empresa tem sobre ela, inclusive sobre a cooperativa e os cooperados. Desta forma, podem-se definir as formas de departamentalização que viabilizam as maneiras de se organizar, ou efetuar o agrupamento correspondente;

b) autoridade: pode ser caracterizada como uma forma de dar ordens e subsequentemente exigir a obediência de seus subordinados;

c) comunicação: envolve a ação entre o emissor e o receptor (transmitir e receber a mensagem);

d) decisão: determinação ou resolução que se sobrepõe algo.

\section{ESTRUTURAS COOPERATIVAS (DEPARTAMENTALIZAÇÃO)}

A departamentalização é uma imposição do crescimento das empresas, pois sua principal finalidade é a de proporcionar meios para o seu crescimento e desenvolvimento racional, de acordo com Oliveira (2012):

a) departamentalização por turno: trata de períodos ou turnos em atividades contínuas, em uma mesma unidade organizacional. Ela é voltada para níveis mais baixos de hierarquia na cooperativa;

b) departamentalização funcional: é a mais utilizada pelas cooperativas, pois trata da atividade diferente alocada em um mesmo complexo a fim de atingir um mesmo objetivo;

c) departamentalização territorial: este segmento é destinado às organizações que atuam em diversas localidades ou regiões, sendo supervisionadas por um executivo ou gestor a fim de se atingir um mesmo objetivo;

d) departamentalização por produtos ou serviços: refere-se à maneira como a organização irá organizar-se respeitando o produto ou serviço que será exercido;

e) departamentalização por grupos de cooperados ou clientes: atividades alinhadas conforme as necessidades dos clientes da cooperativa ou dos 
cooperados, para atender diferentes nichos de mercado. Desta forma, facilitase a coordenação dos resultados, permitindo mais flexibilidade, facilitando a utilização máxima da captação dos recursos;

f) departamentalização por projetos: essa denominação diz respeito a atribuições por um período temporário. Após o término do projeto, a equipe envolvida volta as suas tarefas cotidianas. Essa departamentalização conta com um gestor responsável, que coordena todo ou parte da execução do projeto;

g) departamentalização matricial: refere-se à responsabilidade compartilhada, envolvendo gerentes que assumem responsabilidades em diversos setores funcionais. Para que isso flua perfeitamente, deve haver confiança para atingir os objetivos;

h) departamentalização por unidades estratégicas de negócio: pode ser considerada como um conjunto de tarefas que trabalham juntas tendo um objetivo em comum. Essa departamentalização é comum nas cooperativas, pois é capaz de sistematizar suas estratégias de negócios de forma a proporcionar um aumento na receita. Nota-se, também, mais flexibilidade no plano de gestão da empresa, aprimora a utilização dos recursos e posiciona suas oportunidades no mercado em que trabalha;

i) departamentalização por processos: as atividades são ligadas para atingirem os objetivos. Assim, devem ser especificadas dentro de um processo que corresponde às tarefas, aos departamentos, às equipes, classificando as funções a serem realizadas, criando, dessa forma, maior valor para o cliente;

j) departamentalização mista: é a mais utilizada, pois parte da realidade que a empresa está vivenciando, ou seja, a departamentalização que melhor se adéqua ao estilo de vida dela.

\section{ESTRUTURAS MODERNAS}

O mercado contemporâneo está se desenvolvendo com uma grande velocidade, alterando padrões para aperfeiçoar os mecanismos e quebrando metodologias do passado. Nota-se que essa realidade perfaz com que o presente traga cada vez mais tecnologias eficientes e desta forma torne-se diferente do passado. A era da informação influencia qualquer tipo de organização, seja ela em um modelo estrutural, cultural ou comportamental. Desta forma, a atual realidade temporal busca por excelência com ênfase na participação, no comprometimento, na produtividade e na competitividade.

As cooperativas em si buscam sempre as melhores práticas modernas para abordar dentro de sua estrutura. As metodologias, as técnicas e os processos das cooperativas devem 
estar em perfeita interligação às diversas partes e atividades, proporcionando uma administração estruturada, baseada em indivíduos, pois esses representam o principal foco de conhecimento, informação e decisão (OLIVEIRA, 2012).

O crescimento das organizações cooperativistas acarreta uma maior complexidade estrutural e operacional, o que cobra de seus dirigentes e administradores a competência para gerir seu negócio, obtendo mais capacitação e especialização (INSTITUTO BRASILEIRO DE GOVERNANÇA CORPORATIVA, 2015a).

\section{GOVERNANÇA CORPORATIVA}

A governança corporativa surgiu a fim de estabelecer normas que regulamentassem o relacionamento dentro de uma empresa, para liderar e monitorar as ações de seus gestores, preservando os interesses de seus acionistas controladores, acionistas minoritários e acionistas administradores, facilitando o acesso a recursos.

A Governança Cooperativa avança em todo o mundo porque contribui para a
longevidade e perenidade das cooperativas, aumenta o seu valor, gera mais confiança
junto a todos os públicos relacionados, atrai o melhor capital (de qualidade e com
custo mais baixo) e, assim, alavanca de forma saudável o seu crescimento. As
melhores práticas de Governança Corporativa proporcionam maior transparência e
qualificam os relacionamentos entre cooperados, Conselho de Administração,
Diretoria, Auditoria Independente e Conselho Fiscal, contribuindo para reduzir os
riscos e harmonizar os conflitos de interesses presentes em todas as instituições.
(INSTITUTO BRASILEIRO DE GOVERNANÇA CORPORATIVA, 2015a, p. 19).

Os estudos sobre governança corporativa nas obras de Berle e Means, em Modern Corporation and Private Property (1932) e, posteriormente, Jensen e Meckling, em Theory of the Firm: Managerial Behavior, Agency Costs and Ownership Structure (1976), tiveram como motivador a separação entre propriedade e controle. Nesse pensar, a separação entre propriedade e gestão se torna um obstáculo para que o executivo principal seja o responsável direto do efeito riqueza da ação permitindo a apropriação dos benefícios das decisões por parte dos demais públicos interessados na organização. Também, reduz os custos e problemas no processo de tomada de decisão coletiva e promove mais eficácia na função controle.

Para Williamson (1996), a governança corporativa permite mediar os interesses da organização, de seus proprietários e da sociedade como um todo. Além disso, a temática da governança corporativa, a partir de objetos de estudo com temáticas voltadas para alocação de risco, especialização, risco moral, eficiência, produtividade e desempenho, gestão nas cooperativas agropecuárias, empresas familiares, valor financeiro de mercado dentre outros, é abordada, cronologicamente, por Alchian e Demsetz (1972), Fama e Jensen (1983), Hansmann (1996), Costa, Azevedo e Chaddad (2012) Ferreira et al. (2013) e Silva Junior, Silva e Silva (2013).

Nesse sentido, é imprescindível a adoção de ações bem-definidas, alinhadas aos 
princípios da governança corporativa e que possa evidenciar um norte a que as organizações devam seguir, a fim de agregar novos valores e práticas eficientes na gestão. A governança corporativa visa a promover transparência nas informações e transações, viabilizando investimentos e agregando valor às empresas. Desse modo, oferecer segurança aos investidores no que tange ao gerenciamento da organização é baseada em um conjunto de métodos eficientes que auxiliam na comunicação dos atos dos gestores nas organizações

Segundo Andrade e Rosetti (2006), a governança corporativa consiste em um padrão de comportamentos, com o objetivo de monitorar as organizações por intermédio de mecanismos normativos, definidos em estatutos legais, termos contratuais que conduzem ao gerenciamento eficaz.

Governança corporativa é o conjunto de práticas que tem por finalidade otimizar o desempenho de uma companhia ao proteger todas as partes interessadas, tais como investidores, empregados e credores, facilitando o acesso ao capital. A análise das práticas de governança corporativa aplicada ao mercado de capitais envolve, principalmente: transparência, eqüidade [sic] de tratamento dos acionistas e prestação de contas. (COMISSÃO DE VALORES MOBILIÁRIOS, 2002, p. 1).

A governança corporativa estabelece estratégias definidas, de como as sociedades podem ser monitoradas e controladas, estabelece poder de decisão, estrutura decisória, ciclo sustentável de crescimento e externalidade. Um bom sistema de governança corporativa, de acordo com Andrade e Rosetti (2006), ajuda a fortalecer as empresas, reforça competências, amplia as bases estratégicas da criação de valor, é fator de harmonização de interesses, aumentando a confiança de seus investidores.

A definição dos princípios da governança apresenta conceitos precisos e claros, segundo o Instituto Brasileiro de Governança Corporativa (2015b), os princípios básicos compreendem:

a) transparência: divulgar para as partes interessadas as informações que sejam de seu interesse e não apenas impostas por leis ou regulamentos, especialmente aquelas que envolvem ações econômico-financeiras, que causam impacto nos negócios, envolvem risco, ou as que norteiam a ação gerencial e que conduzem à criação de valor. Que os gestores desenvolvam o desejo de informar e não a obrigação de fazê-lo;

b) equidade: caracteriza-se pelo tratamento justo e igualitário a todos os sócios e às demais partes interessadas, que cada ação seja representada pelo seu voto, evitando fraudes contra acionistas minoritários, ou vantagem em um negócio para outro;

c) prestação de contas: é responsabilidade explícita dos agentes de governança, que são os sócios, os administradores (conselheiros de administração e executivos/gestores), os conselheiros fiscais que devem prestar contas de sua 
atuação, a quem os elegeu, e responder pelos seus atos referentes ao seu mandato, corroborando o princípio da transparência;

d) responsabilidade corporativa: os agentes de governança devem zelar pela sustentabilidade e perenidade das organizações, incorporando considerações de ordem social e ambiental na definição dos negócios e operações. A empresa deve oferecer oportunidades de emprego, qualificação e diversidade da força de trabalho, melhoria da qualidade de vida por meio de ações educativas, culturais, assistenciais e de defesa do meio ambiente.

O processo de governança somente surtirá resultados se esta for a essência da organização, tem que existir de maneira intrínseca e endógena, manifestada em cada indivíduo da organização. De nada adianta projetos bem-estruturados, divulgados e ilustrados se não houver participação efetiva por parte de todos os envolvidos no negócio; isso deve fazer parte da consciência corporativa e de uma mudança no processo cultural da organização.

O modelo de estrutura de governança utilizado usualmente pelas cooperativas segue embasado na Lei n. 5.764, de 16 de dezembro de 1971, Lei das Cooperativas, mas, perante as regras de boas práticas de governança, se tornam um tanto obsoletas (BRASIL, 1971).

A aplicação da governança corporativa nas cooperativas pode ter diferentes origens e necessidades, tais como: questões administrativas, como o desenvolvimento da capacitação profissional; questões estratégicas, como o desenvolvimento de novos negócios; questões legais, como o processo de atuação e de gestão da cooperativa; e questões societárias, como as interações da cooperativa com todos os cooperados (OLIVEIRA, 2012).

Organizações que seguem os princípios da Governança Corporativa profissionalizam sua administração e gestão, ampliam a eficácia de seus controles, mitigam riscos, melhoram sua competitividade e criam um diferencial na condução de seus negócios. Este guia [intitulado Guia das Melhores Práticas de Governança para Cooperativas] surge, portanto, para disseminar as diretrizes e boas práticas de Governança Corporativa para as cooperativas no Brasil e zelar para que os seus mecanismos de decisão evoluam e assegurem a preservação da identidade cooperativa. (INSTITUTO BRASILEIRO DE GOVERNANÇA CORPORATIVA, 2015a, p. 19).

Oliveira (2012, p. 219) elucida sobre governança corporativa:

É o modelo de gestão que, a partir da otimização das interações entre cooperados, conselhos-administração e fiscal-, auditoria-externa e interna e diretoria executiva, proporciona a adequada sustentação para o aumento da atratividade da cooperativa no mercado-financeiro e comercial-e, consequentemente, incremento no valor da cooperativa, redução no nível de risco e maior efetividade da cooperativa ao longo do tempo.

Na estrutura da governança corporativa, o processo de governança corporativa é constituído pelos proprietários, definido por aqueles que se reúnem em assembleia geral, pelo conselho fiscal, pelo conselho de administração e pela diretoria executiva, que é eleita pelo 
conselho de administração (ANDRADE; ROSETTI, 2006). Conforme Instituto Brasileiro de Governança Corporativa (2015a), a governança corporativa contribui para a longevidade e perenidade das cooperativas, contribuindo para agregar valor, gerar mais confiança a todos os envolvidos. Além de proporcionar mais transparência e alinhar os relacionamentos entre cooperados, conselho de administração, diretoria, auditoria independente e conselho fiscal. Dessa forma, constitui-se o salutar crescimento da organização, contribuindo para reduzir os riscos e harmonizar os conflitos de interesses que podem se fazer presentes nas instituições.

\section{METODOLOGIA}

Este estudo engendra-se como um estudo de caso, descritivo com abordagem qualitativa, sendo estruturado em aspectos conceituais e contextuais de fontes teóricas e teórico-reflexivas, sobre estrutura organizacional e governança corporativa em um sistema cooperativo. Os dados coletados ocorreram por intermédio de pesquisa em campo sobre a organização; todavia, as informações encontradas foram comparadas aos aspectos presentes na própria empresa.

Para que fosse possível coletar informações necessárias para o estudo, foram entrevistados os próprios dirigentes e gestores da cooperativa, tendo acesso a documentos de registro pertencentes à empresa. Por conseguinte, realizou-se diagnóstico referente ao modelo de estrutura organizacional e práticas relacionadas à governança corporativa, levando em consideração sua importância para a melhoria e adequação do desempenho de uma empresa cooperativa agroindustrial situada no Estado de Mato Grosso do Sul. Optou-se pelo anonimato do lócus deste estudo para a garantia do resguardo ético. A referenciação da empresa em questão dá-se ao longo do manuscrito apenas como "cooperativa".

\section{ANÁLISE E DISCUSSÃO DOS DADOS}

\section{DESCRIÇÃO DA ORGANIZAÇÃO}

Instigados pelo desejo mútuo do desenvolvimento e em defesa das atividades de seu negócio, como a venda da produção agropecuária, produtores rurais do município de Nova Andradina, MS, decidiram unir forças a fim de valorar mais seu produto. Partindo dessa união, foi criada uma cooperativa em 1981. Ela atua em Nova Andradina e em municípios do entorno e iniciou suas atividades com o intuito de industrializar e comercializar a produção de algodão e milho dos pequenos produtores da região.

Decorrente da escassez e posterior crise do algodão, a cooperativa começou a investir no mercado leiteiro, captando leite in natura de produtores situados na região, com o intuito 
de estruturar a atividade. Com o fortalecimento do setor, e grande aceitação dos cooperados, a cooperativa investiu na construção de um laticínio, localizado no município de Batayporã, MS. As atividades foram iniciadas com uma capacidade de processamento de 35.000 litros por dia, e, em alta produção, chegou a operar em sua capacidade máxima. Além da captação do leite in natura, produz o queijo muçarela, produto de muita aceitação na região.

Em meados dos anos de 1990, a cooperativa inaugurou uma loja veterinária, e, por conseguinte, um supermercado, disponibilizando uma diversidade de produtos e insumos a preços mais acessíveis, com o intuito de atender as necessidades dos cooperados e possibilitar melhorias em sua atividade. Com o intuito de maximizar a gama de insumos e variabilidade de produção, foi criada uma fábrica de rações, que atende os cooperados no seu processo produtivo, constituindo mais uma fonte de produção.

A estrutura organizacional da cooperativa foi desenvolvida pelos seus dirigentes, constituída por intermédio de uma hierarquia e seguindo a essência do estatuto social da sociedade em estudo. Essa mesma estrutura foi formada pelo conselho de administração, composta de cinco membros, sendo a diretoria executiva e o conselho fiscal, como órgão fiscalizador, composto de três membros efetivos e três suplentes.

A Figura 1 apresenta a estrutura organizacional atual da cooperativa, localizada em Nova Andradina, MS, objeto deste estudo.

Figura 1 - Estrutura organizacional da cooperativa localizada em Nova Andradina, MS

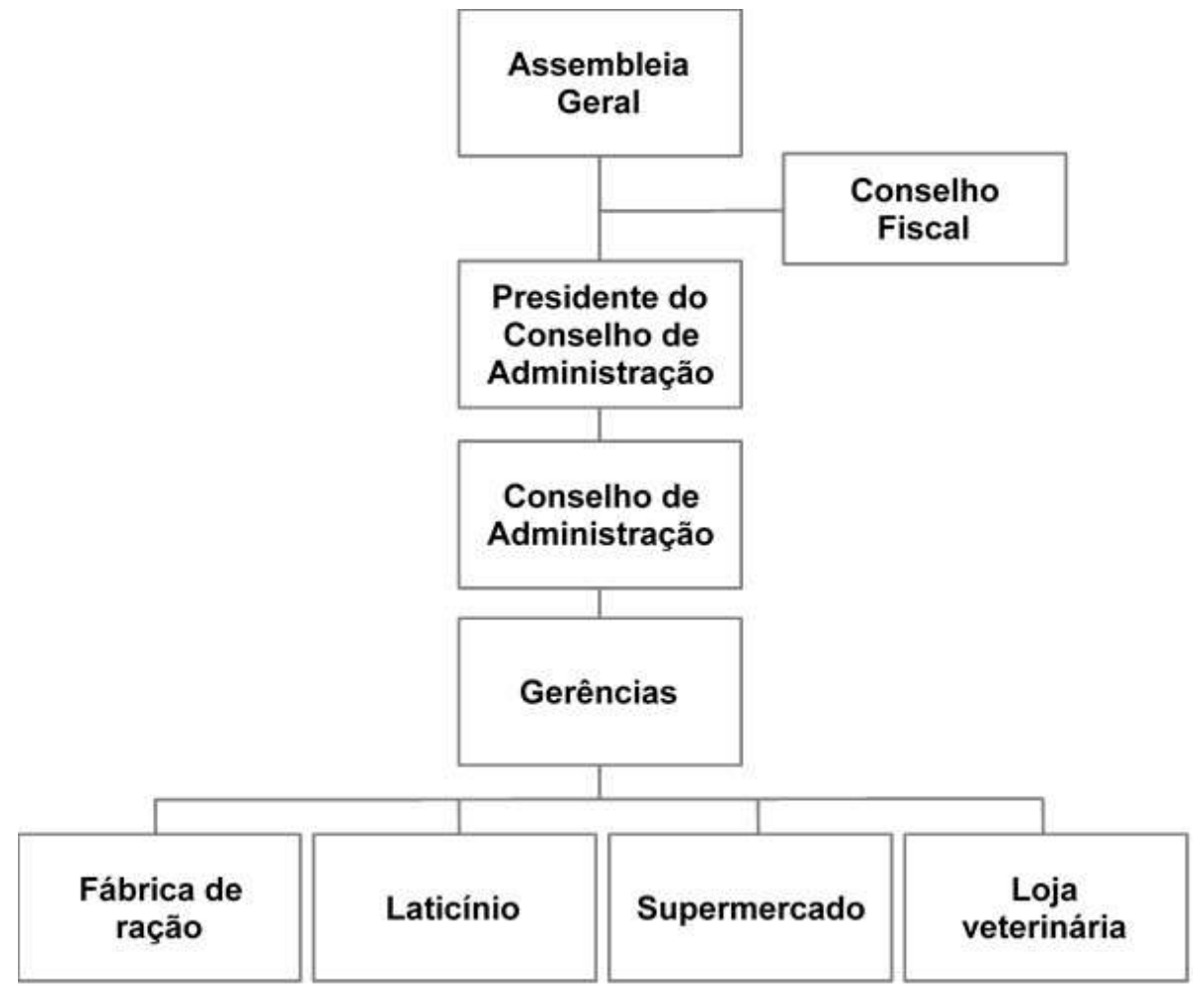

Fonte: elaborada pelos autores, 2018. 
Diante do que foi exposto, Pagnussatt (2004) afirma que, em relação ao modelo estrutural de uma organização, mesmo amparado por regulamentação clara das atividades, funções bem-definidas, responsabilidades e métodos operacionais bem-estruturados, não constitui ferramenta suficiente para assegurar uma gestão eficaz, proposta a garantir sua perenidade. A eficácia faz-se atuante à medida que exista a junção desses atributos aliados às práticas de governança. Colocados em ação por pessoas com perfis adequados aos cargos e comprometidas com a realização desse processo.

A cooperativa é constituída por 161 cooperados e 352 produtores que realizam a entrega de matéria-prima, mas não são associados dela. Apresenta, também, cerca de 70 funcionários vinculados ao supermercado, à loja veterinária, ao laticínio e à fábrica de ração. Após a associação, o produtor passa a utilizar os benefícios pertinentes ao cooperado, desde o desconto na aquisição de produtos, assistência técnica na produção, convênios com farmácias, instituições de ensino até o plano de saúde.

A organização em estudo faz uso da departamentalização mista, pois une diversos fatores dentro dessa categoria (Figura 2). Sendo elas: a funcional, que tem suas atividades agrupadas de acordo com a função; a territorial, que trata das unidades de laticínio, veterinária e fábrica de ração, que são controladas e gerenciadas por um grupo organizacional que se faz presente na matriz, ou seja, no supermercado. Outra em destaque dentro desta empresa é a de produtos e serviços, que trata de uma mesma linha de produção ligada a um mesmo departamento, por exemplo, os pedidos para a produção dentro da unidade fábrica de ração são feitos na loja veterinária. Uma das mais importantes é a departamentalização por grupo de cooperados e clientes, que atende as necessidades de cada indivíduo em um determinado ramo que ele se encontra. Por fim, a unidade estratégica de negócio, que trata de matriz e filiais, trabalhando juntos, com um mesmo objetivo, para maximizar a receita e aprimorar o desenvolvimento igualitário. 
Figura 2 - Uso da departamentalização mista da cooperativa localizada em Nova Andradina, MS

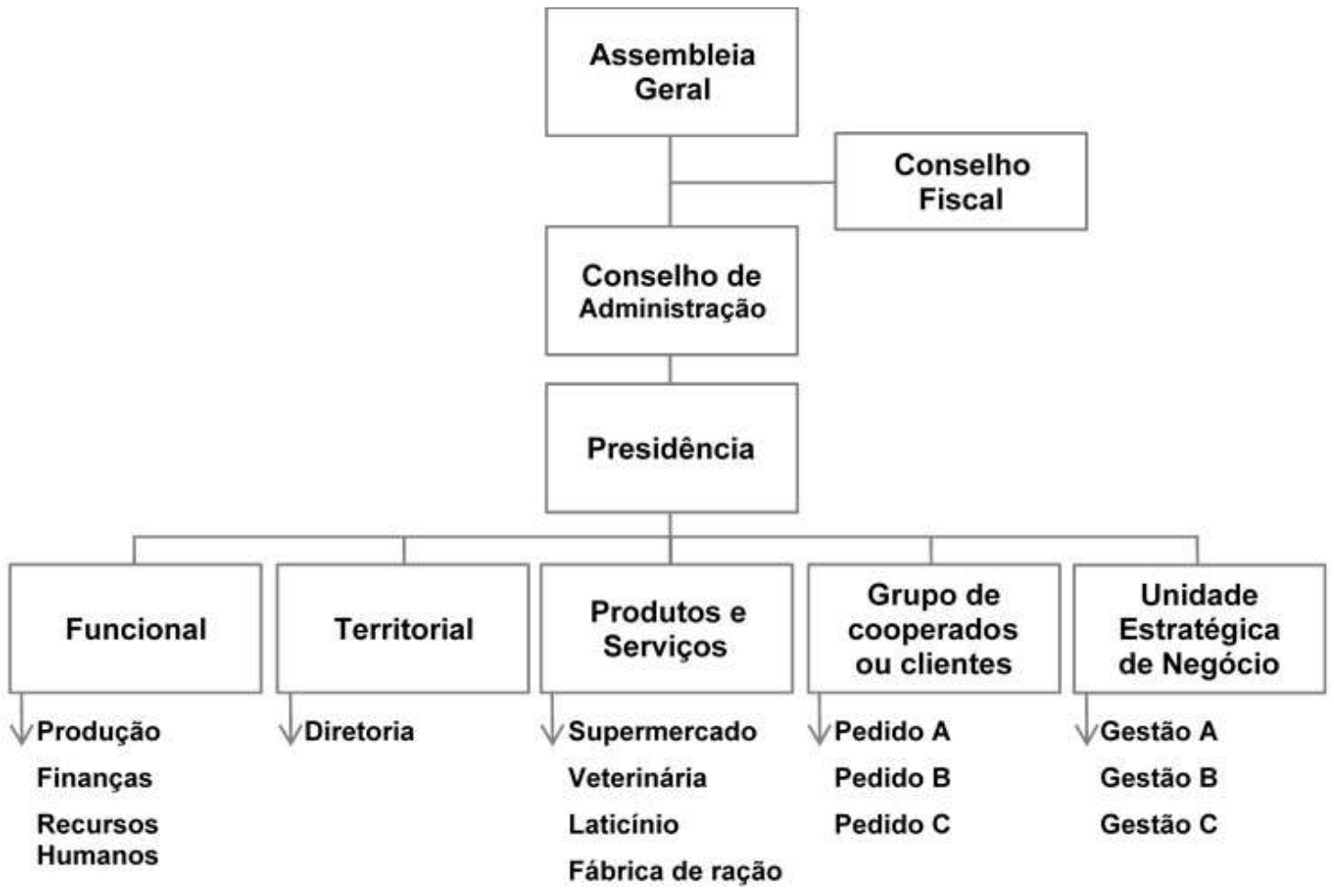

Fonte: elaborado pelos autores, 2018.

Destaca-se a necessidade de acompanhamento do planejamento estratégico, no que se refere aos cronogramas estabelecidos, de forma a constituir alinhamento entre orçamento, execução e provisão de receitas. Visto que as decisões são manifestadas mediante reuniões direcionadas a um propósito definido, ou divulgadas em momento único em assembleia geral.

\section{GOVERNANÇA CORPORATIVA}

Como destacam Costa, Chaddad e Azevedo (2012), as cooperativas agropecuárias brasileiras enquanto organizações econômicas apresentam como característica uma estrutura de propriedade difusa, com direitos vagamente definidos. Além disso, possuem uma estrutura hierárquica e atuam em atividades econômicas variadas, o que permite relacioná-las como organizações complexas. Assim, os autores citados recomendam que essas firmas, com a finalidade de aumentar a probabilidade de sua existência, deveriam promover a separação entre propriedade e gestão.

No caso estudado, o cooperado é o proprietário dos recursos produtivos que mantém o negócio, e, conforme o estatuto, possui direito e deveres, entre eles, o direito de participar dos atos da cooperativa. No aspecto analisado, alguns princípios básicos de governança se fazem presentes, como transparência, equidade, prestação de contas e responsabilidade corporativa, que são atos inegociáveis que uma cooperativa deve manter, objetivando 
publicidade aos associados.

Como primeira ação para que a governança corporativa possa ser instituída e efetiva, é necessária a constituição de um conselho consultivo, a fim de analisar a situação da cooperativa e estudar quais medidas poderão ser adotadas ou aperfeiçoadas. Algumas ressalvas são pertinentes, como a utilização de medidas preventivas sobre os conflitos de interesses, devendo ser desenvolvidas normas que visem a sua inibição, ou procedimentos de como resolvê-los.

TRANSPARÊNCIA

A cooperativa mantém sua transparência estabelecida dentro de seus parâmetros, demonstrando seus processos, arquivos, prestação de contas e dados de forma transparente a todos os envolvidos no negócio dessa organização. A proibição da utilização ou divulgação de informações privilegiadas é obrigatória para os sócios e conselheiros de administração, diretores, conselheiros fiscais, membros de órgãos técnicos e consultivos e deve estar contemplada no estatuto social ou regimento interno. Verifica-se a necessidade da adequação desses dois aspectos a serem apontados à diretoria.

EQUIDADE

De acordo com o que é estabelecido em seu estatuto, a cooperativa em questão determina direitos iguais para diretores, sócios e cooperados. A assembleia é a instância máxima de deliberação e acaba sendo crucial que haja participação em massa de seus associados. É recomendado que a cooperativa estabeleça uma política de relacionamento com seus cooperados, por intermédio de visitas em suas propriedades, a fim de estar mais próximo das necessidades deles. Nota-se que essa política pode ocorrer também por meio do desenvolvimento de núcleos por regiões, com reuniões mensais e atividades que possibilitem a inserção da família do cooperado na cooperativa, despertando o senso de parceria e propriedade.

Em sua assembleia, tanto anual quanto de eleição, todos os sócios ativos têm direito ao voto, contudo, ressalta-se que todo sócio pode constituir uma chapa de candidatura para diretoria, desde que haja pelo menos quatro anos filiado a esta organização.

PRESTAÇÃO DE CONTAS

A prestação de contas é um dever necessário para que haja transparência. Para isso, a cooperativa realiza reuniões e encontros de cooperados, pelo menos uma vez por ano, com o intuito de mobilizar seu espírito cooperativista, para somar esforços para atingir objetivos comuns que beneficiam a todos. No entanto, percebe-se a resistência de alguns cooperados 
em participar efetivamente, e enxergar a cooperativa como sua propriedade, primando somente retorno do seu capital, e não contribuindo de forma a gerar benefício coletivo. Para tanto, é necessária mais sinergia por parte dos administradores, a fim de desenvolver uma educação cooperativista e promover o espírito de união e participação.

\section{RESPONSABILIDADE}

A responsabilidade abordada dentro da organização é bem-específica quando o assunto é hierarquia, cada supervisor assume uma responsabilidade necessária para dar sequência ao seu fluxo de trabalho, começando desde a diretoria e cooperados até ao "chão de fábrica" que assume deveres e obrigações para atingir e superar os resultados estipulados.

Ressalta-se a necessidade de uma aproximação entre auditoria independente e conselho fiscal, e não se limitando o contato na apuração do encerramento do exercício. É recomendado, seguindo o código de boas práticas de governança, desenvolver uma agenda para compartilhar informações úteis para verificar se as operações realizadas e os serviços prestados correspondem aos especificados nos documentos contábeis da cooperativa. Como também orientar, na possibilidade de futuramente implantar um comitê de auditoria para desenvolver trabalho juntamente com a gestão da cooperativa.

Outro ponto a destacar é a criação de um regimento interno para os conselheiros, com o objetivo de normatizar suas ações e atos, pautados nas boas práticas de governança, realizando avaliações, certificando-se de sua aplicabilidade, e, se possível, determinar medidas punitivas caso não seja seguido. Dessa forma, ela tenta aplicar responsabilidades também na área social e ambiental da organização, definindo os negócios e operações, assim conseguindo oferecer oportunidades de emprego, qualificar e diversificar a força de trabalho, melhorar a qualidade de vida por meio de ações educativas, culturais, assistenciais e de defesa do meio ambiente.

\section{SUGESTÕES DE MUDANÇA}

Com base nos dados apresentados, é sugerida uma adequação na estruturação da cooperativa, com a inclusão de comitês. A Figura 3 apresenta uma sugestão de organograma. 
Figura 3 - Sugestão de organograma para a cooperativa de Nova Andradina, MS

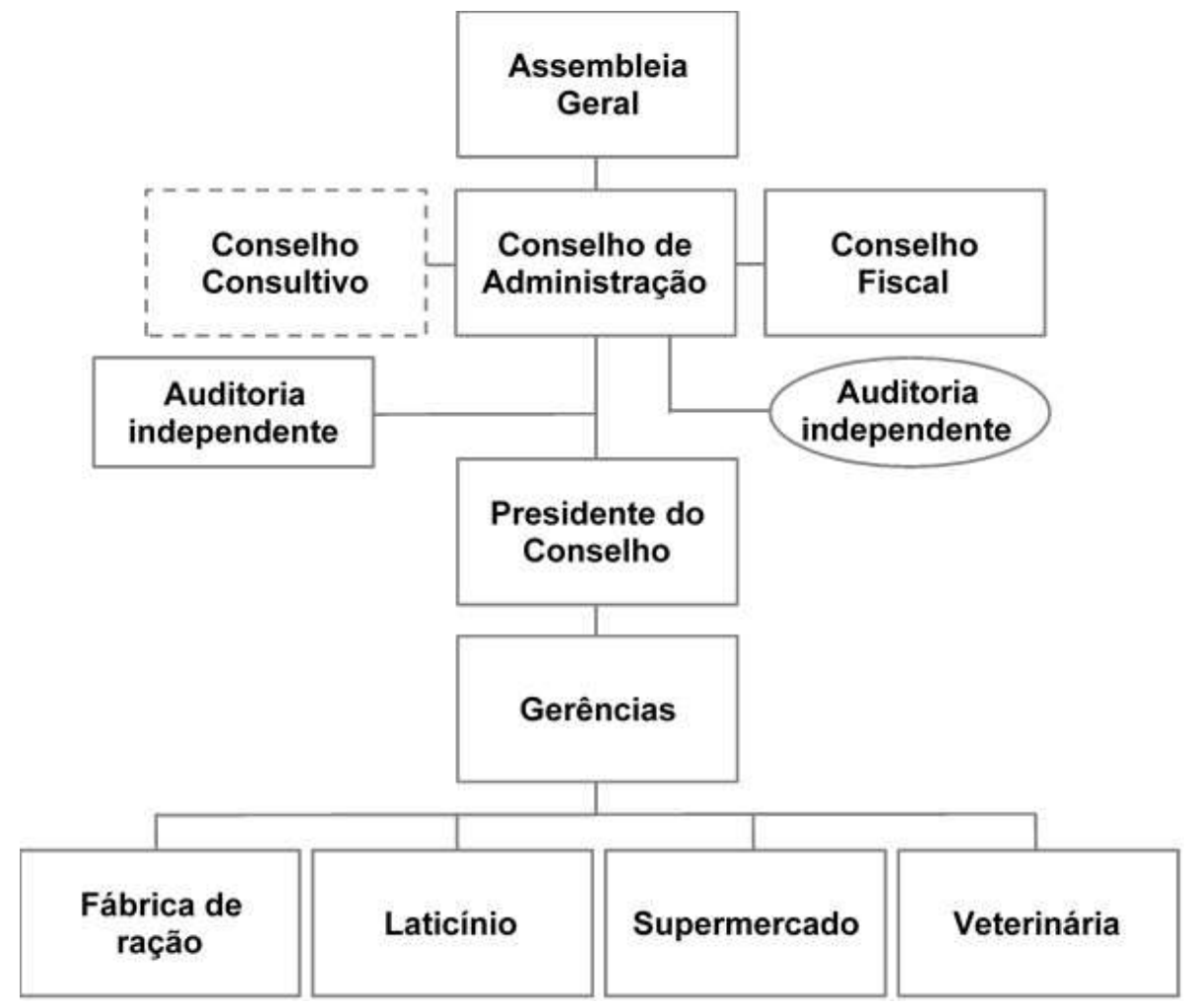

Fonte: adaptado do Instituto Brasileiro de Governança Corporativa (2015a).

Conforme estudo realizado por Costa, Chaddad e Azevedo (2012), 48\% das cooperativas agropecuárias brasileiras pesquisadas pelos autores não promoviam a separação entre propriedade e gestão. Isto é, nessas organizações, os proprietários não são desvinculados das decisões de gestão. Acrescenta-se que Saito e Silveira (2008) afirmam que não há modelos ainda com fundamentação teórica segura que incluam prescrições para decisões ótimas acerca de termos-chave em governança corporativa, como estrutura de capital e conselho de administração, como também se verifica uma carência de fundamentação teórica sobre temaschave da governança corporativa, em especial a relação com o desempenho.

Sendo assim, esse organograma foi elaborado com base nas boas práticas de governança corporativa, identificando assim a necessidade da criação desses comitês, que devem ter ação limitada a fim de assessorar o conselho de administração. Logo, é necessário aderir a melhorias no processo organizacional da cooperativa, no aspecto da educação continuada, a fim de alinhar objetivos dos sócios com os gestores e realizar divulgação dessas práticas em relatório anual dessas melhorias alcançadas. Essa medida demonstra transparência da cooperativa com os seus associados e demais stakeholders.

A cooperativa poderá instituir, de forma objetiva e consensual, programas de capacitação com o programa de formação de dirigentes e conselheiros na área de capacitação em governança cooperativa e gestão de cooperativa. Nota-se a necessidade de planejamento 
de sucessão dos dirigentes, visando à preparação de gestores futuros. É recomendada a estruturação de um planejamento estratégico, reformulado anualmente com projetos preestabelecidos, com metas determinadas, aplicação de recursos e confrontação do previsto com o realizado. Esse trabalho deve ser desenvolvido conjuntamente entre conselho de administração e diretoria executiva no sentido de documentar procedimentos de forma clara e objetiva, promovendo assim uma gestão assertiva, utilizando a governança da cooperativa como norte.

Para que a governança possa ser instituída, é necessário que a cooperativa estabeleça distinção entre o conselho de administração e a diretoria executiva em seus documentos constitutivos. De maneira a evitar precocemente conflitos de interesses, e que suas ações estejam alinhadas a fim de promover a valoração do capital dos proprietários. Com base nos dados supracitados, é recomendado realizar medidas para adequação ao código de boas práticas de governança, dentre elas, criarem estratégias juntamente com a diretoria executiva, para gerenciar riscos de forma mais efetiva. É necessário, também, analisar a possibilidade de criar uma estrutura de auditoria interna e estabelecer formas de avaliação dos conselheiros, amparadas por processos formais bem-definidos, conduzidas pelo presidente do conselho.

\section{CONSIDERAÇÕES FINAIS}

Conclui-se que o objetivo proposto fora alcançado de forma satisfatória. O estudo em questão traz benefícios com a transcrição de informações da estrutura organizacional de uma cooperativa e fornece subsídios para sua melhoria, expondo as teorias e como vem sendo abordada em seu aspecto organizacional, no qual foi ramificado em diversas ideologias, tendo como a principal abordagem a governança corporativa que possibilita que os demais desafios sejam superados por intermédio de suas diretrizes, contribuindo, assim, para uma gestão transparente, sólida e durável.

O contexto abordado traz o desafio de uma mudança na estrutura organizacional, e na própria cultura, partindo dos cooperados e gestores que buscaram desenvolver ou ampliar os processos e as práticas referentes à tomada de decisões, otimizando a comunicação e a relação dos envolvidos, aperfeiçoando o conhecimento da gestão e maximizando a transparência dos administradores e do próprio negócio.

Como apresentado, a organização já faz uso de alguns temas abordados na governança coorporativa, e, se referindo aos aspectos burocráticos à cooperativa, cumpre o que é determinado por lei, estando regida por seu estatuto. Contudo, foram citados possíveis mudanças e ajustes na sua estrutura organizacional, adequando as funções, as modalidades de controles internos, qualificando os gestores, líderes e cooperados, para que a empresa flua em prol de seu desenvolvimento. 


\section{REFERÊNCIAS}

ALCHIAN, A. A.; DEMSETZ, H. Production, information costs, and economic organization. The American Economic Review, New York, v. 62, n. 5, p. 777-795, 1972. Disponível em: <https://business.illinois.edu/josephm/BA549_Fall\%202010/Session\%205/Alchian_Demsetz\% 20\%281972\%29.pdf>. Acesso em: 13 dez. 2018.

ANDRADE, A. ROSSETTI, J. P. Governança corporativa: fundamentos, desenvolvimento e tendências. 2. ed. São Paulo, Atlas, 2006.

BERLE, A. A.; MEANS, G. Modern corporation and private property. New York: MacMillan, 1932.

BRASIL. Presidência da República. Lei n. 5.764, de 16 de dezembro de 1971. Define a Política Nacional de Cooperativismo, institui o regime jurídico das sociedades cooperativas, e dá outras providências. Diário Oficial [da] União da República Federativa do Brasil, Brasília, DF, 16 dez. 1971. Não paginado. Disponível em:

<http://www.planalto.gov.br/ccivil_03/Leis/L5764.htm>. Acesso em: 8 maio 2018.

CHIAVENATO, I. Administração: teoria, processo e prática. 4. ed. Rio de Janeiro: Elsevier, 2007.

COMISSÃO DE VALORES MOBILIÁRIOS. Recomendações da CVM sobre governança corporativa [cartilha de governança]. Rio de Janeiro, 2002. Disponível em:

<http://www.cvm.gov.br/export/sites/cvm/decisoes/anexos/0001/3935.pdf>. Acesso em: 8 maio 2018.

COSTA, D. R. M.; AZEVEDO, P. F.; CHADDAD, F. R. Determinantes da separação entre propriedade e gestão nas cooperativas agropecuárias brasileiras. Revista de Administração (São Paulo), São Paulo, v. 47, n. 4, p. 581-595, dez. 2012. Disponível em:

<http://www.scielo.br/pdf/rausp/v47n4/a06v47n4.pdf>. Acesso em: 13 dez. 2018.

COSTA, M. C. F.; SOUZA, B. S. S.; FELL, A. F. A. Um estudo da estrutura organizacional e as mudanças organizacionais: proposta de um novo modelo. Navus, v. 2, n. 1, p. 57-74, 2012. Disponível em: <http://navus.sc.senac.br/index.php/navus/article/download/62/40>. Acesso em: 8 maio 2018.

FAMA, E. F.; JENSEN, M. C. Separation of ownership and control. The Journal of Law \& Economics, Chicago, v. 26, n. 2, p. 301-325, 1983.

FERREIRA, R. N. et al. Governança corporativa, eficiência, produtividade e desempenho. RAM: Revista de Administração Mackenzie, São Paulo, v. 14, n. 4, p. 134-164, 2013. Disponível em: < http://www.scielo.br/pdf/ram/v14n4/v14n4a06.pdf>. Acesso em: 13 dez. 2018.

HANSMANN, $\mathrm{H}$. The ownership of enterprise. Cambridge: The Belknap Press of Harvard University Press, 1996. 
INSTITUTO BRASILEIRO DE GOVERNANÇA CORPORATIVA. Guia das melhores práticas de governança para cooperativas. São Paulo, 2015a. Disponível em:

<http://www.ibgc.org.br/userfiles/2014/files/Publicacoes/GUIA_DAS_MELHORES_PRATICAS_ DE_GOVERNANCA_PARA_COOPERATIVAS.pdf>. Acesso em: 8 maio 2018.

INSTITUTO BRASILEIRO DE GOVERNANÇA CORPORATIVA. Código das melhores práticas de governança corporativa. 5. ed. São Paulo, 2015b. Disponível em:

<http://www.ibgc.org.br/userfiles/2014/files/codigoMP_5edicao_web.pdf>. Acesso em: 8 maio 2018.

JENSEN, M. C.; MECKLING, W. H. Theory of the firm: managerial behavior, agency costs and ownership structure. Journal of Financial Economics, Amsterdam, v. 3, n. 4, p. 305-360, 1976. Disponível em: <https://ac.els-cdn.com/0304405X7690026X/1-s2.0-0304405X7690026Xmain.pdf?_tid=88482e93-ac21-41d3-908d-

34fdc265ccc3\&acdnat=1544724108_6d1661033fd60a3d759d24183aaacc96>. Acesso em: 13 dez. 2018.

MÜLBERT, A. L.; MUSSI, C. C.; ANGELONI, M. T. Estrutura: o desenho e o espírito das organizações. In: ANGELONI, M. T. (Org.). Organizações do conhecimento: infra-estrutura, pessoas e tecnologia. São Paulo: Saraiva, 2008. p. 62-78.

NADLER, D. A.; TUSHMAN, M. L. A organização do futuro. HSM Management, São Paulo, n. 18, p. 58-67, 2000.

OLIVEIRA, D. P. R. Manual de gestão das cooperativas: uma abordagem prática. 6. ed. São Paulo: Atlas, 2012.

PAGNUSSATT, A. Guia do cooperativismo de crédito: organização, governança e politicas corporativas. Porto Alegre: Sagra Luzzatto, 2004.

SAITO, R.; SILVEIRA, A. D. M. Governança corporativa: custos de agência e estrutura de propriedade. Revista de Administração de Empresas, São Paulo, v. 48, n. 2, p. 79-86, 2008. Disponível em: <http://www.scielo.br/pdf/rae/v48n2/v48n2a07.pdf>. Acesso em: 13 dez. 2018.

SANTOS, A. A. M.; SILVA, D. S. L.; GUIMARÃES, E. A. Departamentalização e os principais tipos. Revista Científica Intermeio, Fortaleza, ano 2, n. 3, p. 43-55, 2014. Disponível em: $<$ http://www.fafor.edu.br/pesquisa/arquivos/Revista_Intermeio_n3_Junho_2014.pdf >. Acesso em: 8 maio 2018.

SBRAGIA, R. Algumas características da estrutura matricial. In: MAXIMIANO, A. C. A. et al. (Org.). Administração do processo de inovação tecnológica. São Paulo: Atlas, 1980. p. 147163.

SILVA JUNIOR, A.; SILVA, P. O. M.; SILVA, A. R. L. Sistemas de valores e implicações na governança corporativa em um grupo empresarial familiar. Organizações \& Sociedade, Salvador, v. 20, n. 65, p. 239-260, 2013. Disponível em: 
<http://www.scielo.br/pdf/osoc/v20n65/v20n65a04.pdf>. Acesso em: 13 dez. 2018.

VASCONCELLOS, E.; HEMSLEY, J. R. Estrutura das organizações: estruturas tradicionais, estruturas para inovação e estrutura matricial. 2. ed. São Paulo: Pioneira, 1997.

WILLIAMSON, O. E. The mechanisms of governance. Oxford: Oxford University Press, 1996. 